\title{
PESQUISA EM EDUCAÇÃO AMBIENTAL E QUESTÕES EPISTEMOLÓGICAS: A PERMANÊNCIA E A RENOVAÇÃO
}

\author{
Eunice Trein ${ }^{1}$ \\ Rosa Maria Feiteiro Cavalari ${ }^{2}$
}

Resumo: No presente artigo apresentamos os resultados das discussões ocorridas no âmbito do Grupo de Discussão de Pesquisa (GDP) Pesquisa em EA e Questões Epistemológicas, durante a realização do VII Encontro de Pesquisa em Educação Ambiental (VII EPEA), em Rio Claro, no período de 07 a 10 de julho de 2013, a partir do tema Problematizando a Temática Ambiental na Sociedade Contemporânea. Assim sendo, além do relato dos onze trabalhos apresentados e discutidos nos dois dias de atividades do GDP, procuramos, neste artigo, resgatar e apresentar algumas conclusões elaboradas em Encontros anteriores, ou seja, no V e VI EPEAs. Esse resgate nos permitiu vislumbrar a permanência e a renovação das temáticas das pesquisas, bem como da trajetória do próprio GDP. Procuramos, ainda, apresentar as condições objetivas sob as quais a pesquisa em educação e, particularmente, em educação ambiental ocorre, atualmente, e os desafios a serem enfrentados pela área para a constituição e consolidação do campo ambiental, particularmente no que se refere à sua epistemologia.

Palavras-chave: Pesquisa em EA. Questões Epistemológicas. Educação Ambiental.

\section{RESEARCH IN ENVIRONMENTAL EDUCATION AND EPISTEMOLOGICAL ISSUES: PERMANENCE AND RENOVATION}

Abstract: In this paper we present the results of the discussions occurred in the Group Discussion Research (GDP) - EA Research and Epistemological Issues - during the VII Meeting of Research in Environmental Education ( VII EPEA), in Rio Claro City, between 07 to 10 July 2013, from the theme Discussing Environmental theme in Contemporary Society. Thus, In addition to addressing the eleven papers presented and discussed during the two days of activities GDP, seek, in this article, rescue and drop some conclusions elaborated in previous meetings, ie, V and VI in EPEAs. This rescue has allowed us to glimpse the permanence and renewal of thematic research, as well as the trajectory of GDP itself. We seek also present the objective conditions under which research in education and particularly in environmental education is currently, and the challenges faced by the area for the establishment and consolidation of the environmental field, particularly with regard to its epistemology.

Keywords: Research in EA. Epistemological Issues. Environmental Education.

\footnotetext{
${ }^{1}$ Professora Associada I, da Universidade Federal Fluminense (UFF), Rio de Janeiro, Brasil, eunicetrein@ig.com.br

2 Professora Assistente Doutora, da Universidade Estadual Paulista “Júlio Mesquita Filho" (UNESP) Câmpus de Rio Claro, São Paulo, Brasil, rosamfc@rc.unesp.br
} 


\section{INVESTIGACIÓN EN EDUCACIÓN AMBIENTAL Y CUESTIONES EPISTEMOLÓGICAS: PERMANENCIA Y RENOVACIÓN}

Resumen: En este artículo se presentan los resultados de los debates ocurridos en el ámbito del Grupo de Discusión de Investigaciones (GDP) Investigaciones en EA y Cuestiones Epistemológicas, durante la realización del VII Encuentro de Investigación en Educación Ambiental (VII EPEA), en la ciudad de Río Claro, en el período de 07 a 10 de julio de 2013, a partir del tema Problematizando la Temática Ambiental en la Sociedad Contemporánea. Así, además de la presentación de once trabajos discutidos durante los dos días de actividades del GDP, en este artículo buscamos rescatar y presentar algunas conclusiones obtenidas en las reuniones anteriores, es decir, V y VI EPEAs. Este rescate nos ha permitido vislumbrar la permanencia y la renovación de las temáticas de las investigaciones, así como la trayectoria del propio GDP. Buscamos, también, presentar las condiciones objetivas bajo las cuáles ocurre la investigación en la educación y, en particular en la educación ambiental, actualmente, además de los desafíos que enfrenta el área por la constitución y consolidación del campo ambiental, en particular con respecto a su epistemología.

Palabras clave: Investigación en EA. Cuestiones Epistemológicas. Educación Ambiental.

\section{Introdução}

Este texto expressa a retomada dos debates que ocorreram durante a apresentação dos trabalhos selecionados no VII EPEA, realizado no período de 07 a 10 de julho de 2013, em Rio Claro-SP, inscritos para apresentação no Grupo de Discussão de Pesquisa (GDP) Pesquisa em EA e Questões Epistemológicas.

Durante as discussões, muitas questões se evidenciaram como recorrentes, uma vez que já haviam aparecido em encontros anteriores (TREIN, 2012; FLORIANI, 2009), outras sinalizaram para novas reflexões, que consolidam e ampliam o campo de pesquisa da Educação Ambiental.

Com o intuito de situar o leitor e de contextualizar as discussões realizadas no GDP nos Encontros anteriores, apresentamos, ainda que de maneira breve, dentre as várias conclusões resultantes dos debates realizados no V e VI EPEAs, duas que nos parecem bastante significativas.

Assim, em seu artigo Educação Ambiental e epistemologia: conhecimento e prática de fronteira ou uma disciplina a mais?, resultante das discussões realizadas no âmbito do GDP Pesquisa em EA e Questões Epistemológicas durante a realização do V EPEA, em São Carlos, em 2009, Dimas Floriani (2009, p.200) afirma que

Novas atitudes se fazem necessárias para se superar o monopólio epistemológico na EA, pelas razões expostas, embora incontáveis obstáculos persistam no interior das disciplinas, nos diversos campos do conhecimento. Trata-se de desenvolver novas culturas epistemológicas, sem a pretensão de criar um novo paradigma hegemônico. 
Por sua vez, Eunice Trein (2011, p.87) no artigo Pesquisa em Educação Ambiental e Questões Epistemológicas: questões levantadas no GDP, que sistematiza as discussões ocorridas no GDP, durante o desenvolvimento do VI EPEA, realizado em Ribeirão Preto, em 2011, afirma que entende como relevante a continuidade dos GDPs como "espaço de pesquisa e sistematização histórica da produção acadêmica sobre a EA", mas alerta para a necessidade de

[...] superar certa perspectiva linear, descritiva dos objetos, métodos e
procedimentos da pesquisa, e explicitar sentidos e interesses a ela
subjacentes. A materialidade histórica que engendra os campos do saber não
pode ser ocultada, pois a ampliação do conhecimento hoje contribui para
desenvolver as forças produtivas e também potencializa o desenvolvimento
de forças destrutivas, solapando a bases materiais e sociais de manutenção
da vida. Essas contradições implica reconhecer que a produção do
conhecimento é uma produção social e, portanto, carrega uma dimensão
ideológica e um compromisso de classe. Explicitar isso é parte do
compromisso ético-político do pensamento crítico (TREIN, 2011, p.87).

O tema central do VII EPEA - Problematizando a Temática Ambiental na Sociedade Contemporânea - e os temas abordados nas conferências proferidas durante o evento fortaleceram a percepção sobre a relevância do GDP que discute as vertentes epistemológicas que sustentam as pesquisas em EA. Ao mesmo tempo em que elas adensam o campo, explicitam as lacunas, as diferenças e as divergências quanto às opções ontoepistemológicas dos pesquisadores. As vertentes epistemológicas reforçadas se expressam na produção científica e na prática docente, na qual se inclui a orientação de dissertações e teses.

Uma questão, de caráter mais geral, que já apontamos em texto anterior (TREIN, 2012), ficou caracterizada nos trabalhos apresentados e nas indagações que os participantes do GDP trouxeram nos dois dias de discussões, ou seja, não podemos elidir o fato de que as pesquisas em EA são marcadas pelas políticas dos Programas de Pós-Graduação, pelas políticas de avaliação da CAPES e, em última instância, pelas políticas públicas que conformam a universidade brasileira. Todas essas políticas carregam, mais e mais, a postura produtivista, que vem caracterizando o campo científico nacional e, também, o internacional.

Hoje, esse é um debate recorrente, não apenas quando o Ministério de Ciência e Tecnologia acrescenta à sua designação o termo Inovação, mas, também, quando as universidades acrescentam a palavra Inovação ao nome de suas pró-reitorias de pósgraduação.

A controvérsia sobre o tema já foi explicitada no campo da Educação, e tem merecido a consideração de diversos autores, entre eles, destacamos: Lopes; Costa (2012), Trein; Rodrigues (2011), Bianchetti; Valle (2011), Rosa (2008), Macedo; Souza (2010), Neves; Pronko (2008), Neves (2010), Sguissardi; Silva Júnior (2009).

De acordo com Bianchetti e Valle (2011, p.6):

No Brasil, as mudanças atingem não apenas as instituições universitárias, mas também repercutem junto aos coordenadores de Programas, aos professores e aos pós-graduandos, que são compelidos a preocupar-se com índices, classificações, fatores de impacto, ranks e, principalmente, a lidar com situações que envolvem um grande grau de competição entre os Programas. 
Ainda de acordo com esses autores, as principais decorrências do predomínio desse modelo são:

[a] predominância do quantitativo sobre o qualitativo, que interfere na produção científica e gera o que é denominado por produtivismo acadêmico [...]. De outra parte, constatamos um descontentamento e um desconforto com a interferência que esta aceleração provoca na produção acadêmica, uma vez que atinge diretamente a qualidade da formação de novos pesquisadores (BIANCHETTI; VALLE, 2011, p.6)

A pressão institucional pela publicação, também é analisada por Rosa (2008, p.109). De acordo com o autor o publicar ou perecer afeta o mundo acadêmico

\begin{abstract}
substituindo a reflexão pela reação, a imaginação pela descrição sociológica, a utopia pela realpolitik, transformando pensadores em burocratas que, em busca de maior produtividade, racionalizam o fazer acadêmico criando sistemas de gerenciamento muitos próximos à lógica industrial, em que a economia de tempo é o ponto-chave do capitalismo moderno.
\end{abstract}

Também em âmbito internacional essas questões são alvo de inúmeros estudos aos quais não vamos nos referir aqui. Apenas como um exemplo dessas preocupações, lembramos o interessante texto do filósofo Nida- Rümelin (2013). Ao se referir às reformas universitárias em curso na Europa a partir da Carta de Bolonha, ele assinala as diferenças que, grosso modo, caracterizaram os três grandes modelos que, historicamente, construíram as universidades europeias e, em especial, a alemã.

Para Nida- Rümelin a universidade, que se constituiu e se consolidou ao longo da Idade Média, baseada na hierarquia e na autoridade centrada na formação de teólogos, juristas e médicos, teve suas bases revolucionadas, no final do século XVIII e início do XIX, pelas ideias do que se chamou a Reforma Humboldt. Aquele foi um momento em que a universidade deixou de ser vista como uma escola, baseada no ensino livresco, onde os conhecimentos se repetiam sem se renovar, para ingressar em um novo patamar, ou seja, o de uma universidade como espaço de produção de conhecimento. A universidade passou a exigir de seus alunos que se qualificassem para as atividades de pesquisa. Foi um momento especialmente voltado para a formação de espíritos livres, capazes de se apropriar de instrumentos que lhes permitissem olhar de forma critica para a realidade social e material.

Segundo o autor citado, a proposta de Humboldt se distanciava da ideia de uma universidade só voltada para a elite. Ela buscava uma formação inclusiva. Seu objetivo era tornar os jovens capazes de julgar, aptos a assumir posições na sociedade em geral. Nida-Rümelin observa que as diferenças entre Humboldt e Bolonha, entre o século XIX e o XXI, se dão principalmente na maneira como a universidade busca atingir o objetivo de superar a cristalização dos conhecimentos, de viabilizar o desenvolvimento científico e tecnológico e de permitir a mobilidade dos indivíduos no interior da Europa.

Para Nida-Rümelin, as reformas de Humboldt e de Bolonha seguem estratégias antagônicas. Se para a proposta humboldtiana era nocivo, prejudicial, que a universidade possuísse objetivos muito pragmáticos, utilitaristas, no processo de pesquisa e ensino, ao contrário, Bolonha vê com desconfiança e desagrado a falta de pragmatismo, a distância entre o fazer acadêmico e as exigências do mercado e do setor produtivo. 
Nos referimos especificamente a esses modelos de concepções sobre as finalidades das universidades porque são os modelos que marcaram fortemente as universidades brasileiras, principalmente as públicas.

Assim, também aqui, hoje, o ensino propedêutico, baseado na pesquisa e baseado em grandes linhas epistemológicas que configuram os campos do saber, é visto como afastado da realidade, pouco produtivo, e as linhas epistemológicas não são encaradas como pré-requisitos no ensino. Estamos vivenciando, também no Brasil, uma separação progressiva entre o ensino e a pesquisa, o que, no nosso entendimento, tem se mostrado prejudicial à consolidação e desenvolvimento da produção do conhecimento em que a compreensão crítica da totalidade social onde o conhecimento é produzido não pode ser negligenciada.

Chauí (1999, p.220) em importante artigo no qual analisa as transformações pelas quais a universidade passou em função de ter se transformado, de uma instituição social em uma organização social, afirma que essa transformação resultou na Universidade Operacional, a qual é "regida por contratos de gestão, avaliada por índices de produtividade, calculada para ser flexível [...] estruturada por estratégias e programas de eficácia organizacional [...]", regida por "normas e padrões inteiramente alheios ao conhecimento e à formação intelectual". Nesta universidade, denuncia a autora:

[...] a docência é pensada ou como habilitação rápida para graduados, que precisam entrar rapidamente no mercado de trabalho, do qual serão expulsos em poucos anos, pois se tornam em pouco tempo em jovens obsoletos e descartáveis; ou então, como correia de transmissão entre pesquisadores e treino para novos pesquisadores. Transmissão e adestramento. Desapareceu, portanto, a marca essencial da docência: a formação (CHAUÍ, 1999, p.221).

Consideramos que o GDP de Epistemologia se mostrou, mais uma vez, como um espaço relevante de resistência ao uso pragmático, fragmentário e eclético da teoria. Ele é um lugar onde foi possível aprofundar as questões apresentadas nas conferências e nos debates que se seguiram a elas, discutir as vertentes epistemológicas presentes nos trabalhos enviados para o GDP, assim como abordar outras questões trazidas pelos participantes, professores e alunos da pós-graduação e da graduação. Pensamos que tudo o que foi discutido nos dois dias do GDP legitimou e explicitou a pertinência da temática do VII EPEA: Problematizando a temática ambiental na sociedade contemporânea.

\section{Os temas e as questões dos trabalhos apresentados no GDP}

O tema mais geral, que apresentamos brevemente acima, e que diz respeito às condições sob as quais a pesquisa em educação e em educação ambiental especificamente ocorre, permeou boa parte das discussões que emergiram no GDP.

Alem dessa questão mais geral, outro tema, que mais uma vez ganhou destaque, foi o que diz respeito à forma justaposta com que aparece a relação entre a educação como prática social e a adjetivação ambiental. Os participantes enfatizaram as dificuldades que encontram em transitar para a prática docente desde os conhecimentos específicos de cada área de formação, pois embora se defenda, há muito tempo, a ideia que a EA é um campo interdisciplinar por excelência, essa perspectiva ainda se apresenta mais como promessa do que como realidade. Muitos observaram que, sem a 
necessária articulação, torna-se difícil a constituição efetiva do campo teórico e metodológico da pesquisa e da prática em Educação Ambiental.

Especificamente, sobre esse tema se posicionaram os autores do único trabalho inscrito $^{3}$ no GDP que relacionou Educação e Ambiental (TO107-1).

No texto em questão, Teixeira e Tozoni-Reis destacam três eixos de reflexão que, no nosso entendimento, necessariamente, devem fazer parte de uma pauta de trabalho dos pesquisadores do campo da EA.

Um primeiro eixo diz respeito à falta de articulação entre as pesquisas realizadas na área da educação em geral e aquelas realizadas na área da EA. Essa questão tem sido recorrente nas reuniões do GT da ANPEd, nos EPEAs e outros espaços onde são discutidos os rumos da EA. Embora o grupo de pesquisa liderado por Tozoni-Reis venha se ocupando dessa temática, mesmo assim ela continua presente nos debates.

Goergen (2010, p.18), em seu artigo Teoria e ação no GT Educação Ambiental da ANPEd: partilhando algumas suspeitas epistemológicas, no qual analisa os trabalhos de pesquisa desenvolvidos pelos integrantes do GT 22 sugere "uma reflexão aprofundada sobre o conceito e os sentidos de educação, bem como sobre as teorias educacionais que, veladamente, informam as pesquisas do GT Educação Ambiental".

Essa reflexão, de acordo com o autor é importante por duas razões: "porque 'educação' é um conceito polissêmico, sendo empregado em muitos sentidos não só diferentes, mas contraditórios e porque só o delineamento do termo 'educação' confere densidade conceitual epistêmica ao binômio "educação ambiental" (GOERGEN, 2010, p. 28).

No nosso entendimento, isto é devido especialmente à formação no âmbito das licenciaturas, onde as questões da educação estão separadas das questões específicas de cada área. As pesquisas realizadas junto aos professores expressam suas dificuldades em incluir a temática ambiental no currículo escolar como parte do projeto político pedagógico das escolas onde atuam

Assim, Teixeira e Tozoni-Reis em seu texto A educação ambiental e a formação de professores: pensando a inserção da educação ambiental na escola pública (T01071) advertem que:

O objetivo principal deste estudo será o de defender a necessidade de o campo da pesquisa em educação ambiental considerar as contribuições do campo da educação para que o processo formativo do educador ambiental voltado para a inserção da educação ambiental na escola pública seja mais consistente e coerente.

Um segundo eixo de preocupações diz respeito à importância de que as pesquisas em EA explicitem, com clareza, os marcos teóricos que fundamentam seus estudos na área. Os autores apontam para a necessidade de um maior rigor nas investigações sobre as práticas pedagógicas em EA, com o objetivo de dar mais consistência aos resultados das pesquisas e de permitir uma formação mais criteriosa dos professores que atuarão nas escolas.

A necessidade de explicitação clara dos marcos teóricos que fundamentam as pesquisas na área tem sido apontada por alguns autores, como por exemplo, Pato, Sá e Catalão (2009), e Goergen (2010). No primeiro caso, as autoras fazem referência a certa

\footnotetext{
3 Para efeito da elaboração deste texto nos referimos aos trabalhos apresentados no GDP pelo seu respectivo número de inscrição. Os Anais do evento podem ser acessados em http://www.epea.tmp.br/epea2013_anais/
} 
fragilidade metodológica, ao analisar a produção acadêmica em EA do GT 22 da ANPEd, no período de 2003 a 2007. De acordo com as autoras:

[...] pode-se constar que, no geral, a parte referente ao método quase sempre é negligenciada. A maioria dos autores dedica pouca atenção à explicitação da matriz teórico metodológica utilizada em seus estudos, especialmente no diz respeito à descrição do método, deixando a cargo do leitor as devidas inferências. Considera-se que essa omissão fragiliza a produção acadêmica na área [...] (PATO; SÁ; CATALÃO, 2009, p. 231).

Já Goergen (2010, p. 28), também analisando os trabalhos apresentados no GT 22 da ANPed, no artigo já citado, afirma que se pode perceber nos trabalhos analisados "um certo dogmatismo na forma de enunciar os procedimentos metodológicos com base no argumento da autoridade de alguns autores, sem uma argumentação adequada a respeito dos procedimentos sugeridos na sua relação com o objeto investigado".

Ainda de acordo com o autor, fica-se com a impressão que

a opção teórico-metodológica assume, em boa parte dos projetos, uma característica operacional, ou seja, comunica-se ao leitor que será seguido este ou aquele referencial teórico sem um aprofundamento maior a respeito da consistência, da pertinência e também das implicações epistêmicopolíticas da opção assumida (GOERGEN, 2010, p.15).

Cumpre destacar, no entanto, que a carência de uma sólida fundamentação teórico-metodológica não é apanágio da produção teórica em Educação Ambiental. Também no campo da pesquisa em Educação essa carência tem sido notada, tal como apontada, há algum tempo, por teóricos da área, como por exemplo, Warde, 1990; André, 2000; André, 2006; Gatti, 2002. De acordo com a última autora citada

É preciso reconhecer que não temos nos omitido no enfrentamento desses problemas, mas que, por outro lado, nem tudo o que se faz sob o rótulo de pesquisa educacional pode ser realmente considerado como fundado em princípios da investigação científica, traduzindo, com suficiente clareza suas condições de generalidade e, simultaneamente, de especialização, de capacidade de teorização, de crítica e de geração de uma problemática própria, transcendendo pelo método não só o senso comum, como as racionalizações primárias (GATTI, 2002, p. 32).

O terceiro eixo temático, que emerge do texto de Teixeira e Tozoni-Reis principalmente no momento em que ganha a força de lei a inclusão da EA em todos os níveis de ensino, é o que eles expressam em suas conclusões: “[...] existe um distanciamento entre as publicações acadêmicas e científicas produzidas no âmbito da pesquisa em educação ambiental e da formação de professores e o trabalho docente do professor da educação básica".

Provavelmente, outros GDPs tematizaram essas questões que continuam desafiando a área, elas que dizem respeito à necessidade de estabelecermos a relação entre teoria e prática enquanto práxis.

Preocupações semelhantes às que encontramos no texto citado apareceram nas discussões ao longo dos dois dias de reunião. Alunos da graduação sinalizaram para as lacunas em sua formação nos bacharelatos e também nas licenciaturas, onde a necessária articulação entre os conhecimentos específicos de cada área do saber e as questões de caráter mais pedagógico não ocorrem. Observaram, ainda, que fica por 
conta do aluno a responsabilidade de estabelecer as mediações entre as questões da educação e as questões ambientais, o que é fundamental para que a EA ganhe um sentido mais orgânico no ambiente escolar.

Os demais trabalhos apresentados e discutidos no GDP estabeleceram pouco diálogo com os espaços educativos concretos. Algumas vezes, produzindo posturas de caráter prescritivo para o exercício de uma educação ambiental crítica, que, no entanto, não foi suficientemente conceituada.

Em um campo de pesquisa que busca se consolidar, parece-nos que essa é mais uma questão que não deve ser considerada um tema menor. De um modo geral, os trabalhos apresentados se reconhecem como parte integrante da Educação Ambiental Crítica, no entanto, não explicitam suficientemente como a definem e como a vertente epistemológica a que se filiam embasa essa educação e a distingue de outras concepções críticas.

Se entendermos que, ao nos apropriarmos de uma teoria em suas características onto-epistemológicas, na medida em que ela nos permite analisar criticamente a realidade, nos apoderamos de um instrumento capaz de se constituir como força material e, assim, em condições de contribuir para efetivas transformações sociais. A teoria que sustenta nossa reflexão e a forma como nos relacionamos com a prática será tão mais efetiva quanto maior for a coerência interna do corpus teórico com o qual examinamos o real. Nesse contexto, outras questões que mobilizaram os participantes do GDP durante as discussões foram: como lidar com diferentes aportes teóricos sem nos tornamos ecléticos? Como respeitar a congruência interna de uma teoria? Isto, de fato, é necessário? Como dialogar com o pensamento de diferentes autores sem falsear seus pressupostos, conceitos e categorias de análise?

Entre os onze trabalhos encaminhados para o GDP, poderíamos distinguir, ainda, de modo geral, cinco abordagens que enriqueceram a temática da educação ambiental. Dois trabalhos, que em um estágio menos avançado da pesquisa já haviam sido apresentados no VI EPEA, retornaram buscando aprofundar vertentes da chamada epistemologia do sul, na conceituação de Boaventura de Souza Santos ou, como ainda na acepção de Dussel e Freire, também conhecida como epistemologia da libertação.

Camargo e Tonso (T-0211-1) em seu texto Educação ambiental crítica $e$ epistemologia do sul: reflexões sobre 'VivirBien' (Suma Qamaña), se apoiam em Boaventura de Souza Santos, Carlos Walter Porto Gonçalves e Mauro Guimarães para fazer uma crítica ao eurocentrismo, enfatizando a necessidade de que as vozes dos dominados sejam ouvidas. Enfatizaram o desacordo com o modelo capitalista de desenvolvimento e exemplificaram, através da visão de mundo dos povos originários da Bolívia e do conceito de Bien Vivir (Suma Qamaña), a possibilidade de enfrentar a colonialidade dos saberes. Naquele texto, os autores criticam as epistemologias hegemônicas que apontam o desenvolvimento científico como panaceia para os problemas ambientais que assolam as sociedades, principalmente as do hemisfério sul.

Também, resgatando o pensamento latino-americano, César Augusto Costa e Carlos Frederico Loureiro (T0022-1) encontram em Enrique Dussel e Paulo Freire elementos para uma crítica ao pensamento hegemônico. Eles enfatizam a necessidade da constituição de uma educação ambiental crítica, onde o método dialógico de Freire e o método anadialético de Dussel pretendem servir de inspiração para uma leitura renovada do marxismo em apoio à constituição de uma EA que ambicione novas formas de relação entre os seres humanos e a natureza como parte significativa das transformações sociais. 
Seguindo, podemos agrupar três trabalhos que fazem a crítica à modernidade na sua face positivista e pragmática, tal como ela se manifesta na ciência moderna e dá sustentação ao modo de produção capitalista. Os autores (COSTA; LOUREIRO (T0022); SOUZA; CAVALARI (T0097-1); TEIXEIRA; TOZONI-REIS (T0107-1) em seus textos fazem referência à escola e à prática docente, destacando a formação de professores, a interdisciplinaridade e a ética como temas necessários ao enfrentamento concreto da prática de uma EA que se quer crítica e transformadora. Com isso, observamos que esses temas, recorrentes nos encontros sobre EA, comparecem mais uma vez nos debates.

A questão da ética, por sua vez, se afigura como um problema emergente no GDP. Essa temática foi enfocada por Souza e Cavalari em seu texto A ética ambiental na produção teórica (dissertação e teses) em educação ambiental no Brasil (T0097-1). As autoras fazem a crítica ao conceito de ética ambiental, destacando que a ética, como um atributo do fazer humano, contempla a questão ambiental na medida em que reconhece a ética como dimensão material e histórica da produção social da vida. Baseadas em Hans Jonas, buscam distanciar-se de uma perspectiva utilitarista na relação homem-natureza, sem cair, no entanto, no oposto, onde a natureza é entendida como o não humano, de forma idealizada.

Para as autoras:

Valorizar todas as formas de vida, e a natureza não humana em todas as suas manifestações, não implica necessariamente na desvalorização humana, ou em críticas tão severas à espécie como um todo. Parece que se esquece que o ser humano também faz parte da natureza e que, ao renegá-lo, contrapõem-se à própria ideia que se quer defender, ou seja, a valorização de toda a natureza.

Outros trabalhos de cunho mais estritamente teórico analisam diferentes aspectos da modernidade e suas contradições.

Ofélia Agoglia (T0206-1), baseada nos teóricos da Escola de Frankfurt, examina criticamente a modernidade e suas manifestações nos problemas da sociedade capitalista industrial. A autora encontra na Dialética do Esclarecimento, de Adorno e Horkheimer, os elementos teóricos para criticar o domínio da razão instrumental nas relações sociais e nas relações que os homens estabelecem com a natureza, elemento fundante da crise social e ambiental que precisa ser superada.

Também, no texto de Janaína Roberta dos Santos (T0070-1), baseado em autores da Teoria Crítica, encontramos uma crítica ao pensamento moderno, mais especificamente à ciência moderna, na medida em que seu desenvolvimento se faz sob interesses econômicos e mercadológicos. Nesse sentido, a autora conclui que:

A importância da educação ambiental enquanto parte constituinte do amplo
processo educativo. Não apenas enquanto possibilidade de proposição de
novas maneiras de compreendermos e valorizarmos a natureza, mas
principalmente, enquanto estimuladora da crítica e questionamento de um
sistema que conhece para dominar e domina para destruir.

Por fim, mas não menos importante, emerge a temática da estética, contemplada em dois trabalhos. Edilson de Oliveira e Simone A. Buchala (T.0056-2) em seu texto $O$ sistema e a linguagem da educação ambiental: uma proposta de análise, através da análise de discurso, examinam o sistema e a linguagem da educação ambiental, distinguindo o discurso da ciência do discurso da arte, apontando para a relevância da 
dimensão estética da natureza em oposição ao discurso catastrófico e imediatista com que as questões ambientais muitas vezes são apresentadas na EA. Os autores concluem com um apelo a uma formação ampla a ser oferecida aos alunos. Dizem eles:

\begin{abstract}
Fornecendo-lhes uma formação completa e diversificada que passe pelo estudo da língua e das linguagens, da filosofia, das artes, das ciências, considerando as culturas e religiões e apresentando como um dos valores mais complexos a ser respeitado: a relação homem/natureza que no universo mais amplo acaba sendo a mais importante.
\end{abstract}

Também Valéria Ghislati Iared e Haydée Torres de Oliveira (T0104-1), em seu texto Formação de valores estéticos e éticos e o cerrado, baseadas na vertente epistemológica da hermenêutica, aprofundam a reflexão sobre a educação estética como elemento importante para "criar um novo senso ambiental estético e ético"; o que contribuiria para ampliar as "potencialidades transformadoras da educação ambiental".

Ainda os teóricos da Escola de Frankfurt servem de apoio ao trabalho de Leila Cristina A. Barbosa e Carlos Alberto Marques (T0055-1) quando eles discutem uma nova questão em seu texto $O$ princípio da precaução como aporte teórico para a educação ambiental. Os autores, no estudo teórico que desenvolvem, esclarecem as diversas interpretações que o Princípio de Precaução comporta e como vem sendo utilizado em seu sentido mais forte, onde a sociedade é levada a se pronunciar sobre possíveis situações de risco interferindo nas políticas públicas e nas relações públicoprivado. Por outro lado, sua acepção fraca significa a participação que é apenas mitigadora de danos maiores. Leila Cristina A. Barbosa e Carlos Alberto Marques defendem a hipótese de que o Princípio da Precaução, quando tomado em sua radicalidade, se aproxima das vertentes mais críticas da EA e, nesse sentido, eles nos apontam para a potencialidade desse conceito na orientação de áreas do conhecimento como, por exemplo, as ciências da natureza e suas aplicações sociais e tecnológicas.

\title{
3. Considerações Finais
}

Poderíamos dizer que, após este breve relato sobre as questões que emergiram das apresentações de trabalhos e discussões entre os participantes, alguns temas já conhecidos retornaram às discussões, enquanto novos temas despontam como importantes.

Dentre os temas emergentes pode ser citado o da chamada ética ambiental. De acordo com Grün (2007, p.202), "as éticas ambientais têm um enorme potencial subversivo, pois não aceitam o status quo que tornou parte da humanidade dominadora da Natureza e, em consequência, não aceitam também a ordem vigente".

Ainda, de acordo com o autor, "o amplo leque de éticas ambientais dá testemunho de uma grande diversidade de pensamentos e vem ao encontro da também muito diversificada Educação Ambiental" (GRÜN, 2007, p.202)

Assim sendo, a necessidade de se estabelecer novos padrões éticos para nortear a relação sociedade-natureza torna-se imprescindível e urgente, e a Ética, enquanto uma disciplina filosófica, tem importante papel a desempenhar. No entanto, em que pesem essa urgência e necessidade, tematizar essa questão coloca para a Educação Ambiental novos desafios.

Quando advogamos, com muita pertinência, a necessidade de uma ética ambiental, o que exatamente estamos defendendo? Quais referenciais teórico- 
metodológicos lhe dão sustentação? e, sobretudo, em qual epistemologia essa ética está ancorada? sobre qual solo epistemológico ela se erige?

A ética, hoje, independente do adjetivo ambiental, "está entrelaçada à política, sendo área de apreensão e aplicação dos valores sociais. Mas, a política está entrelaçada à ética, pois esta não pode ater-se a critérios técnico-funcionais" (SEVERINO, 2001, p.96).

Assim, nos parece que temos uma pauta significativa de temas provocadores de novas reflexões e que merecem ser aprofundados. No entanto, como fazê-lo?

Além do desafio da superação da fragilidade metodológica, que tem acompanhado a produção no campo da Educação e, consequentemente, da Educação Ambiental, parece que os programas de pós-graduação, assim como os encontros de pesquisadores precisariam de outro formato. Ou seja, deveriam criar espaços para tencionar nossas posições no sentido de explicitá-las, fundamentá-las mais, discuti-las, não apenas em busca do consenso, mas para que, de fato, se tornassem forças materiais de mudança, contornando o produtivismo, o individualismo e a postura competitiva. Afinal, se nos filiamos todos à EA crítica, precisamos saber - crítica de que?

Retornamos ao ponto inicial de nossas reflexões: sob um modelo de universidade que pragmaticamente cobra resultados imediatos, que separa a pesquisa da docência, que direciona pautas de investigação à inovação com potencial mercadológico, como praticar a produção do conhecimento criativo e comprometido com as mudanças sociais e ambientais necessárias a um mundo menos desigual!

\section{Referências}

AGOGLIA, O. La incidencia del proceso de instrumentalización de la razón sobre la emergencia de la crises ambiental. In: ENCONTRO DE PESQUISA EM EDUCAÇÃO AMBIENTAL, 7, 2013, Rio Claro. Anais... [Inédito].

ANDRÉ, M. A pesquisa sobre Formação de Professores no Brasil -1990/98. In CANDAU, V.M. (Org.) Ensinar e Aprender: sujeitos, saberes e Pesquisa (ENDIPE). Rio de Janeiro: DP\&A, 2000. p.257-266.

ANDRÉ, M. Pesquisa em Educação: desafios contemporâneos. Pesquisa em Educação Ambiental, São Carlos, v.1, n.1, p. 43-57, jul/dez. 2006.

BARBOSA, L.C.A.;MARQUES, C.A. O princípio da precaução como aporte teórico para a Educação Ambiental. In: ENCONTRO DE PESQUISA EM EDUCAÇÃO AMBIENTAL, 7, 2013, Rio Claro. Anais... [Inédito].

BIANCHETTI, L.; VALLE, I.R. Produtivismo Acadêmico e Decorrências às Condições de Vida/Trabalho de Pesquisadores Brasileiros e Europeus. In: SIMPÓSIO BRASILEIRO DA ASSOCIAÇÃO NACIONAL DE POLÍTICA E ADMINISTRAÇÃO DA EDUCAÇÃO

(ANPAE) - Políticas Públicas e Gestão da Educação: construção histórica, debates contemporâneos e novas perspectivas, 25, 2011, São Paulo. Anais... São Paulo: ANPAE, 2011. p.1-13. Disponível em:

<http://www.anpae.org.br/simposio2011/cdrom2011/PDFs/trabalhosCompletos/comunicacoesR elatos/0301.pdf>. Acesso em: 11 jan. 2014. 
CAMARGO, T.D'A.; TONSO, S..Educação Ambiental crítica e epistemologia do Sul: reflexões sobre o "vivirbien" (Suma Qamaña) In: ENCONTRO DE PESQUISA EM EDUCAÇÃO AMBIENTAL, 7, 2013, Rio Claro. Anais... [Inédito].

CHAUÍ, M. A universidade em ruínas. In: TRINDADE, H. (Org.) Universidade em ruínas na República dos Professores. Petrópolis: Vozes, 1999.

COSTA, C.A.; LOUREIRO, C.F.Educação Ambiental crítica: contribuições à luz de Enrique Dussel e Paulo Freire. In: ENCONTRO DE PESQUISA EM EDUCAÇÃ̃O AMBIENTAL, 7, 2013, Rio Claro. Anais... [Inédito].

FLORIANI, D. Educação ambiental e epistemologia: conhecimento e prática de fronteira ou uma disciplina a mais? Pesquisa em Educação Ambiental, Rio Claro, v.4, n. 2, p.191-202, jul./dez. 2009.

GATTI, B. A construção da pesquisa em Educação no Brasil. Brasília: Plano Editora, 2002.

GOERGEN, P. Teoria e ação do GT de Educação Ambiental da ANPEd: partilhando algumas suspeitas epistemológicas. Pesquisa em Educação Ambiental, Rio Claro, v.5, n. 2, p. 9-30, jul/dez. 2010.

GRÜN, M. A pesquisa em Ética na Educação Ambiental. Pesquisa em Educação Ambiental, Rio Claro, v.2, n. 1, p.185-206, jan/jun. 2007.

IARED, V.G.; OLIVEIRA, H.T. de Formação de valores estéticos e éticos e o cerrado. In: ENCONTRO DE PESQUISA EM EDUCAÇÃ̃O AMBIENTAL, 7, 2013, Rio Claro. Anais... [Inédito].

LOPES, A.C.; COSTA, H.H.C. A produção bibliográfica em coautoria na área de educação. Revista Brasileira de Educação, Campinas, v.17, n 51, p.717-730, set./dez. 2012.

MACEDO, E.; SOUZA, C.P. de. A pesquisa em educação no Brasil. Revista Brasileira de Educação, Campinas, v.15, n.43, p.166-176, jan./abr.2010.

NEVES, L.M.W.; PRONKO, M.A. O mercado do conhecimento e o conhecimento para o mercado: da formação para o trabalho complexo no Brasil contemporâneo. Rio de Janeiro: EPSJV, 2008.

NEVES, L.M.W. et al. (Orgs.) A direita para o social e a esquerda para o capital: intelectuais da nova pedagogia da hegemonia no Brasil. São Paulo: Xamã, 2010.

NIDA-RÜMELIN, J. Fehlschlag und Erfolg der zweiten großen Universitätsreform in Deutschland. Neue Gesellschaft Frankfurter Hefte. Dietz Verlag. Bonn. Hefte 10, 2013.

Oliveira, E.de; Buchala, S.A. O sistema e a linguagem da Educação Ambiental: uma proposta de análise. In: ENCONTRO DE PESQUISA EM EDUCAÇÃO AMBIENTAL, 7, 2013, Rio Claro. Anais... [Inédito].

PATO, C.; SÁ, L.M.; CATALÃO, V.L. Mapeamento de Tendências na Produção Acadêmica sobre Educação Ambiental. Educação em Revista, Belo Horizonte, v.25, n.3, p.213-233, dez. 2009. 
ROSA, A.R. "Nós e os índices" - um outro olhar sobre a pressão institucional pela publicação. Pensata RAE, São Paulo, vol. 48, n.4, 108-114, out/dez, 2008.

SANTOS, J.R. dos. A Ciência Moderna e o domínio da natureza: contribuiç̃̃es filosóficas para pensar a crise ambiental. In: ENCONTRO DE PESQUISA EM EDUCAÇÃO AMBIENTAL, 7, 2013, Rio Claro. Anais... [Inédito].

SEVERINO, A.J. Educação, Sujeito e História. São Paulo: Olho D’ Água, 2001.

SOUZA, H.A.L. de; CAVALARI, R.M.F. A "ética ambiental” na produção teórica (dissertações e teses) em Educação Ambiental no Brasil. In: ENCONTRO DE PESQUISA EM EDUCAÇÃO AMBIENTAL, 7, 2013, Rio Claro. Anais... [Inédito].

SQUISSARDI, V.; SILVA JUNIOR, J. dos R. Trabalho intensificado nas federais: pósgraduação e produtivismo acadêmico. São Paulo: Xamã, 2009.

TEIXEIRA, L.A,; TOZONI-REIS, M.F. de C. A Educação Ambiental e a formação de professores: pensando a inserção da Educação Ambiental na escola pública. In: ENCONTRO DE PESQUISA EM EDUCAÇÃO AMBIENTAL, 7, 2013, Rio Claro. Anais... [Inédito].

TREIN, E.; RODRIGUES, J. O mal-estar na Academia: produtivismo científico, o fetichismo do conhecimento - mercadoria. Revista Brasileira de Educação, Campinas, v.16, n.48, p.769792, set./dez. 2011.

TREIN, E. Pesquisa em Educação Ambiental e questões Epistemológicas: questões levantadas no GDP. Pesquisa em Educação Ambiental, Rio Claro, v.7, n.2, p.79-89, jul/dez. 2012.

WARDE, M. J. O papel da pesquisa na pós-graduação em educação. Cadernos de Pesquisa, São Paulo, n.73, p.67-75, mai.1990.

Artigo submetido em 11/04/2014

Artigo aprovado em 09/06/2014 